\title{
Protease-Activated Receptor PAR-4: An Inducible Switch between Thrombosis and Vascular Inflammation?
}

\author{
${ }^{1}$ Institut für Pharmakologie and Klinische Pharmakologie, Klinikum \\ der Heinrich-Heine-Universität Düsseldorf, Düsseldorf, Germany \\ 2 Experimentelle Hämostaseologie, Klinik für Anästhesiologie, \\ Operative Intensivmedizin und Schmerztherapie, \\ Universitätsklinikum Münster, Münster, Germany \\ ${ }^{3}$ Center of Drug Absorption and Transport (C_DAT), Institut für \\ Pharmakologie, Universitätsmedizin Greifswald, \\ Greifswald, Germany \\ ${ }^{4}$ Medizinische Klinik III, Kardiologie, Klinikum der Eberhard-Karls- \\ Universität Tübingen, Tübingen, Germany
}

Anke C. Fender ${ }^{1,2}$ Bernhard H. Rauch ${ }^{3}$ Tobias Geisler $^{4} \quad$ Karsten Schrör $^{1}$

Address for correspondence Anke C. Fender, PhD, Klinik für Anästhesiologie, Operative Intensivmedizin und Schmerztherapie, Abt. Experimentelle Hämostaseologie, Universitätsklinikum Münster, Mendelstr. 11, 48149 Münster, Germany (e-mail: afender@uni-muenster.de).

\begin{abstract}
Keywords

- thrombin

- thromboinflammation

- protease-activated receptor

- vascular

- antagonist

Thrombin triggers activation of platelets through protease-activated receptor 1 (PAR-1) and PAR-4. Both receptors are widely expressed and exert multiple platelet-independent functions. PAR signalling contributes to healing responses after injury, by promoting cytokine activity and cellular growth and mobility. Uncontrolled PAR activation, however, can prevent timely resolution of inflammation, enhance thrombogenic endothelial function and drive adverse remodelling. The specific role of PAR-4 in thromboinflammatory vascular disease has been largely underestimated, given the relatively limited expression of PAR-4 in non-platelet cells under healthy conditions. However, unlike PAR-1, PAR-4 expression adapts dynamically to numerous stimuli associated with thromboinflammation, including thrombin, angiotensin II, sphingosine-1-phosphate (S1P), high glucose and redox stress, suggesting expression is switched on 'at need'. Prostacyclin negatively regulates PAR-4 expression at the post-transcriptional level, which may serve to fine-tune thrombin responses and limit these to the injury site. PAR- 4 elicits inflammatory, mitogenic and proliferative actions not only in response to thrombin but also to numerous other inflammatory proteases, and can cross-talk with other receptor systems such as S1P and adenosine receptors. Accordingly, PAR-4 has emerged as a candidate player in vessel disease and cardiac post-infarction remodelling. Currently, PAR4 is a particularly promising target for safer anti-thrombotic therapies. Recent studies with the PAR-4 antagonist BMS-986120 lend support to the concept that selective antagonism of PAR-4 may offer both an effective and safe anti-thrombotic therapy in the acute thrombotic setting as well as an anti-inflammatory strategy to prevent long-term progressive atherosclerotic disease in high-risk cardiovascular patients.
\end{abstract}




\section{Introduction}

The serine protease thrombin is the key enzyme of the blood coagulation cascade activated upon vessel or tissue injury. A rapidly initiated chain of inflammatory and wound-healing processes serves to prevent further blood loss and restore function. At rest, a non-coagulant barrier surface is provided by the endothelium, which also releases anti-thrombotic factors such as the tissue factor pathway inhibitor and binds (and inactivates) the majority of circulating thrombin by binding to thrombomodulin. As a result of injury or inflammation, exposure of sub-endothelial collagen to blood components enables the first adhesion of circulating platelets to the site of injury via von Willebrand factor, resulting in a platelet aggregate or 'plug' that stops bleeding. During this initiation phase of coagulation, activation of endothelial cells, blood leukocytes and sub-endothelial vascular smooth muscle cells (SMC) and fibroblasts increases surface expression of the potent procoagulant trigger tissue factor (TF). Engagement of circulating coagulation factor (F) VII by TF initiates the sequential proteolysis and activation of a cascade of coagulation factors, culminating in the generation of active factor X (FXa) and thrombin. In the amplification phase, adherent platelets are activated by thrombin and form a platelet aggregate, providing a surface for the activation of other procoagulant factors and procoagulant microparticles. Concomitantly, thrombin sustains and further enhances coagulation factor activation. During the subsequent propagation phase, generation of active thrombin on the surface of activated platelets is amplified, allowing for sufficient production of insoluble fibrin that is cross-linked together with the aggregated platelets into a stable clot. The details of the finely tuned haemostatic pathway have been excellently reviewed recently. ${ }^{1}$

\section{Thrombin Receptors in Platelet Activation}

Platelet activation is a key initiating event in blood coagulation, and thrombin is the strongest known trigger of this process. Human platelet activation by thrombin is mediated through two receptors, protease-activated receptor 1 (PAR-1) and
PAR-4. ${ }^{2,3}$ PARs belong to a family of four known G proteincoupled receptors (GPCRs) with a unique mode of receptor activation. Rather than the ligand engagement typical of other GPCR, PAR activation by thrombin depends on proteolytic cleavage of the $\mathrm{N}$-terminal domain of the receptor, generating a new amino terminus that acts as a tethered ligand to activate the receptor. Diverse serine proteases from immune cells, the coagulation cascade and digestive tract, amongst others, have been reported to activate PAR with different specificities (-Table 1). ${ }^{4}$ PAR-1 was first described, and is the prototypical thrombin receptor on platelets and other cells. PAR-2 is conventionally not considered as a thrombin receptor, responding instead to tryptic enzymes, although high levels of thrombin in excess of $10 \mathrm{U} / \mathrm{mL}$ can reportedly activate PAR-2. ${ }^{5}$ PAR-3 is cleaved by thrombin, but the ability of this receptor to signal autonomously is controversially discussed. It appears to act primarily as a cofactor for the other thrombin-activated PAR, specifically PAR-4 in rodent platelets. ${ }^{6}$

PAR-4 itself is a low-affinity thrombin receptor. The $\mathrm{EC}_{50}$ of PAR-4 for thrombin is 100 -fold higher than that of PAR- $1^{7}$ due to the lack of a specific hirudin-like binding domain. The signalling and desensitization/re-sensitization profiles of PAR-4 are distinct from PAR- 1 and hence the PAR- 4 component of the platelet response to thrombin is slower but more prolonged. Intriguingly, depending on the activating protease, stimulation of PAR-1 and PAR-4 may elicit different responses, providing functional plasticity that may allow for the development of specific PAR-targeting therapies. ${ }^{8}$ A further remarkable feature of PAR-4 is the ability to interact functionally and physically with other receptors, such as PAR-1 or the ADP receptors $\mathrm{P} 2 \times 1$ or $\mathrm{P}_{2} \mathrm{Y}_{12} \cdot{ }^{8-13}$ Such heterodimer formation generally supports mutual receptor activation beyond the individual signalling capacity of each receptor alone, which likely underlies the sustained platelet signalling required for thrombus stabilization. $\mathrm{P}_{2} \mathrm{Y}_{12}$ is the pharmacological target of thienopyridine-type anti-platelet agents such as clopidogrel and prasugrel, ${ }^{14}$ and appears to contribute critically to the steady and sustained rise in calcium and $\alpha_{I I} \beta_{3}$ activation evoked by PAR-4. The response to PAR- 1 activation by contrast involves an acute and short-lived rise in cytosolic calcium and

Table 1 Main characteristics of the known PAR family members

\begin{tabular}{|c|l|l|l|}
\hline & Signalling & Activating proteases & Cellular expression \\
\hline PAR-1 & $\mathrm{G}_{\mathrm{q}}, \mathrm{G}_{12 / 13}, \mathrm{G}_{\mathrm{i}}$ & $\begin{array}{l}\text { Thrombin, FVIla/Xa } \\
\text { trypsin, elastase, plasmin, chymase, } \\
\text { protease3, activated PC, } \\
\text { granzyme A, gingipains }\end{array}$ & $\begin{array}{l}\text { Platelets (h), endothelial and vascular smooth muscle } \\
\text { cells, leukocytes, epithelial cells, fibroblasts, neurons, } \\
\text { mast cells, myocytes, astrocytes }\end{array}$ \\
\hline PAR-2 & $\mathrm{G}_{\mathrm{q}}, \mathrm{G}_{12 / 13}, \mathrm{G}_{\mathrm{i}}$ & $\begin{array}{l}\text { FVlla/Xa, trypsin, tryptase, } \\
\text { elastase, thrombin? }\end{array}$ & $\begin{array}{l}\text { Endothelial and vascular smooth muscle cells, leukocytes, } \\
\text { epithelial cells, fibroblasts, neurons, mast cells, myocytes, } \\
\text { astrocytes, adipocytes }\end{array}$ \\
\hline PAR-3 & $?$ & Thrombin & $\begin{array}{l}\text { Platelets (m), endothelial and vascular smooth } \\
\text { muscle cells, astrocytes }\end{array}$ \\
\hline PAR-4 & $\begin{array}{l}\mathrm{G}_{\mathrm{q}}, \mathrm{G}_{12 / 13} \\
\left(\mathrm{G}_{\mathrm{i}} \text { ?) }\right.\end{array}$ & $\begin{array}{l}\text { Thrombin, cathepsin G, factors Xa and } \\
\text { Vlla, trypsin, gingipains-R }\end{array}$ & $\begin{array}{l}\text { Platelets (h, m) } \\
\text { leukocytes, endothelial and vascular smooth muscle cells, } \\
\text { myocytes, astrocytes, adipocytes }\end{array}$ \\
\hline
\end{tabular}

Abbreviations: $\mathrm{H}$, human; $\mathrm{m}$, mouse.

Note: For detailed reviews, see Han et al, ${ }^{18}$ Shah, ${ }^{22}$ Coughlin, ${ }^{29}$ Napoli et al, ${ }^{33}$ Mahajan et al, ${ }^{39}$ and Traynelis andTrejo. ${ }^{138}$ 
$\alpha_{\text {IIb }} \beta_{3}$ activation, independently of this ADP receptor. ${ }^{9,15-17}$ Accordingly, $\mathrm{P}_{2} \mathrm{Y}_{12}$ receptor inhibition with, e.g. clopidogrel may additionally add to the net response and suppress PAR-4mediated platelet aggregation, while PAR-1-mediated effects are largely unaltered. ${ }^{15}$ This intra-platelet phenomenon, attributable presumably to purinergic feedback, will likely occur primarily when thrombin levels are high, and the functional contribution of PAR- 4 becomes more important. While the ability for receptor cross-talk of PAR-4 (and PAR-1) adds a further level of fine-tuning platelet responses, it at the same time represents another factor to be considered in therapeutic drug development. Current antagonists target receptor monomer function, and it remains to be seen how the formation and signalling of dimers or oligomers are influenced.

\section{Thrombin Receptor Function in Vascular Inflammation and Remodelling}

As detailed above, coagulation culminates in the formation of a fibrin clot, which seals the injury site to prevent further blood loss. However, damage to the surrounding endothelium and structural matrix must also be repaired for restoration of function. ${ }^{18}$ Of the total amount of thrombin generated in the context of blood coagulation, the vast majority is actually formed after clotting is completed, ${ }^{19}$ indicating additional roles. Clotting human plasma generates and releases active thrombin and FXa in sufficient levels to elicit mitogenic and inflammatory responses in cultured vascular SMC. ${ }^{11}$ Both processes are essential for healing and protection from infection. The thrombin-PAR signalling system encompasses multiple functions extending far beyond platelet activation. Direct platelet-independent actions of thrombin on cells within injured tissue, particularly in the vicinity of thrombi, are increasingly seen to contribute to local wound-healing and remodelling responses. As evident from - Table 1, PAR-1 and PAR-4 are widely expressed and respond to a broad range of ligands. Accordingly, involvement in many diverse processes has been reported, including embryonic development, neuropathology, angiogenesis, tumour biology, tissue regeneration, immunity, acute and chronic inflammation, and cardiovascular diseases. ${ }^{1,8,21-33}$

Several endogenous braking systems tightly control thrombin actions, including several serine protease inhibitors that rapidly inactivate circulating thrombin. At the cellular level, thrombomodulin and the endothelial activated protein $C$ receptor (EPCR) cooperate as a tandem 'response converter' to switch thrombin/PAR-1 interactions from a procoagulant to an anti-coagulant interaction ${ }^{\text {in18 }}{ }^{18}$, at least in the settings of an intact, functional endothelium. The endothelial PAR-1/activated protein C ( $\mathrm{aPC}$ ) interaction is a classical example of biased signalling, whereby activation of the same receptor can context dependently result in different signalling responses. PAR- 1 activation by thrombin in the absence of aPC elicits a constellation of proinflammatory responses ${ }^{8,34}$ The mechanisms of the signalling bias may be related to the 10,000-fold greater efficiency for PAR-1 cleavage over aPC cleavage, the requirement for receptor partitioning into caveolar microdomains for effective aPC signaling and distinct intracellular signalling and desensitization events downstream of PAR-1.8,34

Despite the numerous inactivating mechanisms, active thrombin can continue to be released from mural thrombi for up to a week, and high levels of active protease have even been detected within clots at surgery or autopsy.,34 Moreover, thrombin bound to the sub-endothelial extracellular matrix remains functionally active, localized and protected from inactivation by circulating inhibitors; ${ }^{36}$ thus, PAR expressed by nearby cells are likely to be continuously exposed to high levels of thrombin. While increased cytokine activity and cellular growth and mobility are essential to achieve healing and restoration of function, an overshooting or sustained PAR activation conceivably prevents resolution of inflammation, enhances thrombogenic endothelial function and promotes excessive vascular remodelling. For PAR-1, this is supported by the findings of the TRA $2^{\circ} \mathrm{P}$-TIMI 50 trial. ${ }^{37}$ In a subset of patients with peripheral artery disease (PAD), PAR-1 inhibition with the selective antagonist vorapaxar significantly reduced acute limb ischaemia and peripheral revascularization, an effect that appears to be largely attributable to direct effects on vascular or inflammatory cells and independent of anti-platelet actions.

The contribution of PAR-4 to thromboinflammatory vascular pathophysiology has by contrast been underestimated, given the relatively limited expression of PAR-4 in nonplatelet cells under healthy conditions. ${ }^{18,31,33,38-43}$ In earlier studies, we provided the first evidence for the functional expression of all thrombin receptors-PAR-1, PAR-3, PAR-4 and thrombomodulin/EPCR-in human vascular SMC and could demonstrate independent contribution of each receptor to the net migratory, proliferative and inflammatory profile of SMC. ${ }^{23,44-53}$ Intriguingly, PAR-4 appears to be subject to a differential regulation by its primary agonist thrombin, when added at concentrations approximating those released by clotting plasma. ${ }^{20}$ While constitutive expression of PAR-1 remains steady in human vascular SMC of either arterial or venous origin, PAR-4 mRNA levels respond dynamically to thrombin. ${ }^{44,48}$ One speculative possibility is that different thrombin receptors serve distinct functions that are switched on 'at need'.

\section{PAR-4 Regulation as a Novel Stress Response Signal}

Besides thrombin, other stimuli characteristic of vascular injury and inflammation also promote a differential thrombin receptor regulation. ${ }^{23,48,54-62}$ PAR-4 seems particularly sensitive to such signals, suggesting the receptor may represent a type of sensor for pathological stress that responds with marked upregulation from a normally low level of expression under resting conditions. Human arteries, for example, do not respond to PAR-4 activation in situ unless previously stimulated with a cytokine cocktail containing interleukin (IL)- $1 \alpha$ or tumor necrosis factor alpha. ${ }^{63}$ Similarly, we have observed striking induction of PAR-4-but not PAR-1 or PAR-3-in human vascular SMC exposed to elevated extracellular glucose, hydrogen peroxide $\left(\mathrm{H}_{2} \mathrm{O}_{2}\right)$ or angiotensin II (Ang II). ${ }^{23,48}$ 
Additional findings point to a highly dynamic regulation of PAR-4 occurring also in human monocytes exposed to proinflammatory lipid mediators such as sphingosine-1-phosphate (S1P).S1P is released from activated platelets and may enhance responsiveness to thrombin in monocytes via elevated PAR-4 expression resulting in increased levels of cyclooxygenase (COX)-2 at sites of injury. ${ }^{61}$ This unique adaptability in response to stress or inflammatory triggers, i.e. high glucose or S1P, clearly sets PAR-4 apart from other thrombin receptors, which show no such upregulation either at the expression level or in terms of function. Accordingly, high glucose-pre-treated SMC show greater sensitivity to the PAR-4 component of the thrombin response in terms of intracellular calcium mobilization, migration and inflammatory gene expression, while PAR1-mediated responsiveness remains unaltered. ${ }^{48}$

The precise explanation for the unique regulatory control of PAR-4 is slowly being unravelled. One reason might be the distinct chromosomal location of PAR-4 on chromosome $19 \mathrm{p} 12$, while the other thrombin-responsive PAR map to chromosome 5q13. ${ }^{64}$ We have explored the cellular mechanisms of PAR-4 regulation in response to diverse stressors, and have identified a dual control system involving both a transcriptional and post-transcriptional component (summarized in - Fig. 1). Stress-activated PAR-4 transcription occurs in a rapid and sustained manner, ${ }^{23,48}$ converging upon protein kinase $C$ (PKC)-dependent activation of the nuclear factor kappa B (NF-KB). Transcription factor binding analysis identified recognition motifs for NF-KB in the promoter region of PAR-4, but not of other thrombin-sensitive PAR. $^{48}$ This essentially implies a potentially unique role for PAR-4 in settings of inflammatory, redox and/or hyperglycemic stress and in response to certain growth factors. Stabilization of the PAR-4 transcript serves a second checkpoint for selectively regulating PAR-4 abundance. We could identify an important role of the mRNA-binding protein human antigen $\mathrm{R}(\mathrm{HuR})$ in this regard. HuR is a ubiquitously

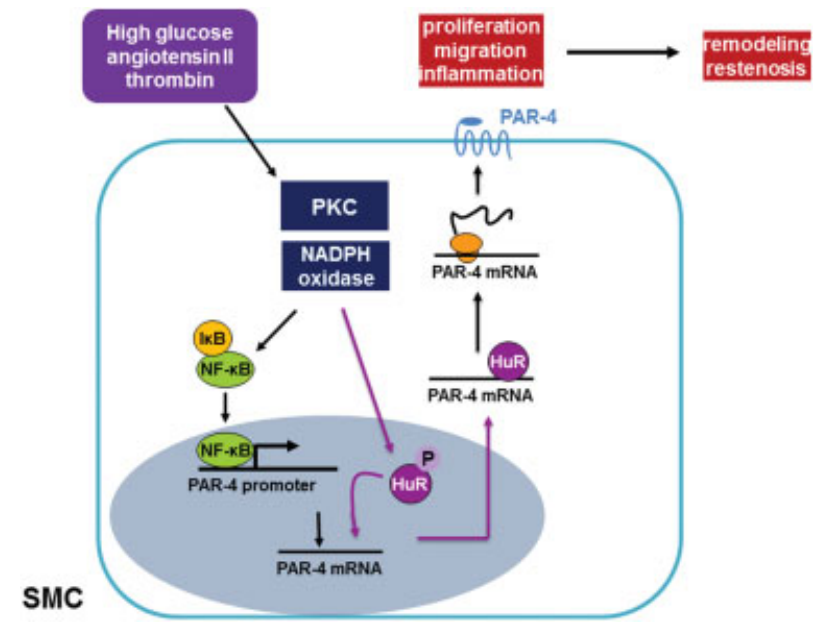

Fig. 1 Schematic summary of PAR-4 regulation in human vascular SMC. PAR-4 expression is controlled by a dual mechanism involving transcriptional upregulation through NF-KB and mRNA stabilization by the mRNA-binding protein HuR. As a consequence, migratory, proliferative and inflammatory responses to PAR-4 activation are augmented, with implications for remodelling and restenosis. expressed mRNA stabilizing factor that is strongly implicated in diverse disorders associated with redox imbalance, inflammation and fibroproliferation. ${ }^{65-67}$ HuR is a member of the embryonic lethal abnormal vision (ELAV) family of RNAbinding proteins, which bind AU-rich elements (AREs) in the 3'-untranslated region (UTR) of target mRNAs. These usually mark the mRNA for rapid degradation. Competitive binding by RNA-binding proteins either stabilizes or destabilizes the mRNA, depending on the upstream input signal. HuR delays target mRNA decay by binding directly to several classes of ARE, including AUUUA repeats, AU regions with interspersed AUUUA and U-rich sequences). A strict requirement for mRNA stabilization is nuclear-cytoplasmic shuttling of the HuR-bound mRNA to the translational machinery, directed by a nuclear shuttling sequence (HNS) and the interaction with nuclear export/import adaptor proteins. We could identify putative ARE in the 3'UTR of human PAR-4, while no such motifs exist in the PAR-1 mRNA. Accordingly, HuR activators such as Ang II and $\mathrm{H}_{2} \mathrm{O}_{2}{ }^{68,69}$ upregulate PAR-4 in human vascular SMC, and HuR-mediated mRNA stabilization contributes also to the stimulatory effects of high glucose on PAR-4 expression in these cells. ${ }^{23}$

Suppression of HuR activity by contrast is seen upon stimulation of cyclic AMP signaling. ${ }^{52,70}$ Accordingly, functional PAR-4 expression in both unstimulated and high glucose-challenged SMC is attenuated by the prostacyclin analogue cicaprost, which impairs PAR-4 transcript stabilization, HuR binding and subsequent cytosolic shuttling in a protein kinase A (PKA)-dependent manner. ${ }^{23}$ At this point, it is worth mentioning that prostacyclin has been for a long time recognized as a functional antagonist of thrombin. ${ }^{18}$ By opposing thrombin's prothrombotic actions as well as its stimulatory effects on cell proliferation, migration, cytokine release and matrix production, prostacyclin helps to control the extent and the site of thrombin action. As we now know, prostacyclin can also dynamically fine-tune thrombin responses by transcriptional and post-transcriptional receptor regulation. ${ }^{23,52,53}$ Induction of COX-2 with subsequent increase of prostaglandin production might serve as an early response after injury, ${ }^{71,72}$ to control the local actions of thrombin and prevent excessive vessel remodelling beyond the injury site. Interestingly, PAR signalling per se can upregulate COX-2 in several cell types including vascular SMC, ${ }^{73}$ endothelial cells ${ }^{74}$ and monocytes, ${ }^{61}$ adding a further, self-limiting, level of regulation.

\section{PAR-4 at the Nexus of Inflammatory Signalling Systems}

The dynamic, context-dependent regulation of PAR-4 in cell types associated with stress responses-including endothelial cells, neutrophils, monocytes and macrophages as well as CD4 $\mathrm{T}$ cells and B lymphocytes ${ }^{56,75-79}$-could conceivably direct responses to coagulant protease generated upon injury or to proteases released from inflammatory cells. PAR-4 activation is a candidate checkpoint for the recruitment of neutrophils $^{78,80}$ and $\mathrm{T}$ cells ${ }^{76}$ and hence plays an important role in the inflammatory response to tissue damage and the defence against possible infection. PAR-4 is thus ideally positioned as 
potential functional switch in settings of thromboinflammation, ${ }^{81}$ a concept further supported by its ability to respond to a spectrum of inflammatory activating proteases and to interact with other receptor systems associated with proinflammatory and prothrombotic processes. For example, besides thrombin and FXa, PAR-4 responds to the mannan-binding lectin-associated serine protease- 1 (MASP-1). The MASP-1/PAR-4 interaction has been particularly well-defined in the context of endothelial activation during microbial defence, triggering inflammatory reactions as part of the immune response against extracellular pathogens. ${ }^{82,83}$ Cathepsin G, a serine protease released from neutrophils and mast cells, is a further inflammatory activator of PAR- $4,{ }^{81,84}$ During enhanced neutrophil mobilization and activation, cathepsin G, via PAR-4, promotes thrombin-independent platelet activation, ${ }^{84,85} \mathrm{cel}$ lular proliferation ${ }^{86}$ and monocyte-endothelial interaction. ${ }^{87}$

PAR-4 is increasingly recognized to interact at the functional level with other thromboinflammatory systems such as the S1P pathway or the $\mathrm{P}_{2} \mathrm{Y}_{12}$-ADP receptor. We have found that the signalling lipid S1P selectively increases PAR-4 transcription and cell surface expression in human monocytes, while PAR- 1 is regulated only at the transcriptional level. Thus, solely PAR-4 contributes to the increased chemotactic and inflammatory function of monocytes in the context of elevated S1P. ${ }^{61,88} \mathrm{~S} 1 \mathrm{P}$ is incidentally released by platelets and cells of the vessel wall in response to thrombin and FXa, and is thus closely linked to thromboinflammatory states. ${ }^{89}$ Besides PAR4-mediated monocyte migration, S1P also amplifies thrombininduced expression of COX-2 in human monocytes. ${ }^{61}$ Perhaps PAR-4, rather than PAR-1, is in fact the predominant thrombin receptor directing monocyte recruitment and enhancing local inflammatory responses to thrombin. This hypothesis is supported by a finding made some 30 years ago, i.e. long before PAR-4 was identified. In this study, the chemotactic response to $\alpha$-thrombin was reported to be suppressed by anti-thrombin III, while blocking the active centre or generating gammathrombin via tryptic proteolysis of the procoagulant exosite did not abrogate chemotactic activity. ${ }^{90}$ Since then, gammathrombin, an auto-proteolytic product of $\alpha$-thrombin, has become known as a selective activator of PAR- $4 .{ }^{91}$

A cooperative PAR- $4 / \mathrm{P}_{2} \mathrm{Y}_{12}$ interaction occurring also in other cells besides platelets is plausible, but has not been demonstrated to date. The contribution of purinergic receptors to chronic or acute vascular inflammation, atherosclerosis, restenosis, endotoxemia and sepsis has been excellently reviewed elsewhere. ${ }^{89,92,93}$ Thienopyridine $\mathrm{P}_{2} \mathrm{Y}_{12}$ antagonists reduce systemic levels of several inflammatory markers in atherothrombotic patients, presumably to a large extent via their anti-platelet action. ${ }^{94-98}$ However, $\mathrm{P}_{2} \mathrm{Y}_{12}$ receptors have been detected in vascular SMC, ${ }^{99-101}$ and we have shown transcriptional upregulation of $\mathrm{P}_{2} \mathrm{Y}_{12}$ in SMC response to thrombin. As a consequence, cyclic AMP elevation, IL-6 expression and secretion, and proliferation induced by the $\mathrm{P}_{2} \mathrm{Y}$ agonist 2-MeSADP are augmented in human SMC preexposed to thrombin. This regulatory effect on $\mathrm{P}_{2} \mathrm{Y}_{12}$ expression is mediated predominantly through PAR- 1 and does not appear to involve PAR-4. ${ }^{102}$ However, PAR-4, but not PAR-1, can specifically modify $\mathrm{P}_{2} \mathrm{Y}_{12}$ function through direct inter- action. ${ }^{9,103}$ This is likely to become relevant under conditions of thrombosis and inflammation where both extracellular nucleotides and PAR-4 are increased and expressed by the overwhelming majority of circulating and vascular cells.

\section{Potential Involvement of PAR-4 in Immune Cell Responses in Thromboinflammation}

PAR-4 is expressed and dynamically regulated on monocytes, neutrophils and T-cells, ${ }^{61,104,105}$ and acts as a strong chemottractant and trigger for proinflammatory signaling. ${ }^{105-108}$ Direct PAR-4-mediated actions are therefore likely to contribute to the inflammatory component of repair and remodelling responses after injury, as well as immune defence. Additionally, PAR-4 will conceivably modulate immunity and inflammation indirectly, through platelet-dependent processes.

The idea of platelets as cells of the innate immune system has received increasing attention in recent years. ${ }^{109-112}$ Platelets can interact directly with diverse pathogens including bacteria, fungi and protozoa, or envelop them in a plateletfibrin clot. This can, for example, limit microbial propagation and increase exposure to neutrophil attack ${ }^{113}$ and reduce the viability and virulence of various fungal species. ${ }^{114,115}$ Yet envelopment of microorganisms by platelets and thrombi might also provide protection from innate immune processes and enable their transport to distant sites. Whether procoagulant and inflammatory interactions between platelets and microorganisms thus outweigh the beneficial immune defence function is therefore context-dependent, particularly in settings of anti-platelet therapy which will modulate platelet function and granule content release and accordingly impact on immune responses. ${ }^{116}$ The PLATO study indicated that acute coronary syndrome patients treated with ticagrelor developed fewer lung infections and exhibited a lower mortality risk following pulmonary adverse events and sepsis than patients receiving the less potent anti-platelet agent clopidogrel. ${ }^{117}$ It is, however, currently unknown to what extent adenosine-related actions of ticagrelor, unrelated to its $\mathrm{P}_{2} \mathrm{Y}_{12}$ inhibitory effects, contribute to these actions. By contrast, preoperative use of dual anti-platelet therapy (aspirin plus clopidogrel) has been associated with an increased risk of infection after coronary artery bypass surgery. ${ }^{118}$

Clearly, the contribution of platelet-dependent effects to the net immune response is strongly context-dependent. How PAR- 4 and the novel PAR- 4 blockers fit into this picture remains to be seen. Although the differential pattern of PAR- 1 versus PAR-4 release profiles is not clear, ${ }^{119}$ there is evidence that specifically PAR-4 activation favours the release of certain factors that directly and indirectly influence inflammatory and immune responses. ${ }^{120-122}$ PAR-4-activated platelets, for example, release gremlin- 1 , which subsequently enhances monocyte migration, adhesion and macrophage differentiation. ${ }^{123}$ PAR-4-triggered release of platelet factor 4 (PF4, chemokine CXCL4) has been implicated in the host response to pneumococcal pneumonia; PAR- $4^{-1-}$ mice accordingly show higher bacterial loads and more pulmonary inflammation, attributable to enhanced cytokine release by the pathogen. ${ }^{124}$ By stimulating release of PF4, PAR-4 may, moreover, direct 
macrophage polarization towards the inflammatory M4 phenotype. These exhibit distinct phenotypic and functional characteristics, such as complete loss of the haemoglobinhaptoglobin (Hb-Hp) scavenger receptor CD163. Lack of CD163 renders M4 macrophages unable to upregulate the atheroprotective enzyme heme oxygenase-1 (HO-1) in response to heme stress and fail to effectively clear haemoglobin after plaque hemorrhage. ${ }^{125,126}$ In this way, PAR-4 may be indirectly involved in the platelet/macrophage-dependent inflammatory component of diseases such as atherosclerosis by disturbing the heme stress response. Conceivably, PAR-4 blockade will limit the derailment of macrophage differentiation in this direction.

\section{PAR-4 in Diabetic Vascular Disease}

Elevated extracellular glucose levels are causally involved in the macro- and microvascular complications, in part by promoting SMC proliferation, matrix synthesis and inflammation in diabetics. ${ }^{127-130}$ Hypercoagulability associated with increased thrombin generation and risk of thrombotic vessel occlusion is also a characteristic of diabetes. ${ }^{131-135}$ Our observation that PAR-4 appears to be selectively upregulated by thrombin, high glucose, Ang II and redox-stress, and that high glucose selectively augments PAR-4-mediated migration and inflammatory gene expression in vascular SMC, ${ }^{23,48}$ suggested its unique role in the context of diabetes. We confirmed the selective increase in PAR- 4 abundance, with no change in PAR-1, in vessels obtained from diabetic patients at bypass and atherectomy ${ }^{23,48}$ (-Fig. 2). Interestingly, we detected greater PAR-4 receptor expression in venous bypass vessels compared with arterial samples which-in addition to other factors-might contribute to the early thrombus formation in venous bypass grafts. ${ }^{136}$

In a proof-of-concept study, we examined the role of PAR-4 during neointimal hyperplasia in mice with streptozotocininduced type 1 diabetes. Much as we saw with our human samples, diabetic C57Bl/6 wild-type mice exhibited marked increases in vascular PAR-4 abundance ( - Fig. 3a,b) and, in the carotid artery ligation model, developed more profound neointimal remodelling than non-diabetic control animals, while PAR-4-deficient diabetic mice did not exhibit such a strikingly augmented neointimal formation ( $\mathbf{F i g} . \mathbf{3 c}, \mathbf{d}$ ) ${ }^{23}$ In comparison with their wild-type diabetic littermates, PAR- $4^{-1-}$ diabetic mice showed reduced numbers of proliferating cells and less macrophage infiltration. ${ }^{23}$ Non-diabetic PAR-4-deficient mice were essentially comparable to nondiabetic wild-types. These observations support the concept that PAR-4 is minimally involved in vascular inflammatory and proliferative processes under resting, normoglycemic conditions, but becomes functionally relevant when expression increases in pathologically challenged cells, presumably vascular SMC. A contribution of platelets can of course not be excluded since PAR-4 is the predominant thrombin receptor in rodent platelets ${ }^{6}$ and streptozotocin treatment reportedly increases platelet sensitivity to PAR-4, explaining in part the increased propensity for thrombosis in this setting. ${ }^{137}$ Presumably, inhibition of augmented PAR-4 platelet function will contribute to the vascular protection seen in the PAR-4deficient diabetic mice.

\section{PAR-4 in Post-infarction Remodelling}

The interplay between PAR-4 and several vascular and immune cells centrally involved in thromboinflammation is depicted in - Fig. 4. One setting in which this intercellular PAR-4 network has received recent attention is myocardial ischaemia/reperfusion ( $I / R)$ injury. Reperfusion is essential to prevent irreversible injury of the ischemic myocardium and permanent organ dysfunction. However, reperfusion itself induces an acute inflammatory response that is a requirement to initiate healing but can also promote an overshooting fibrotic remodelling that ultimately worsens cardiac function. Mice deficient in PAR-4 display reduced infarct size and better functional recovery in the acute phase following $I / R$, which could be attributed in part to prosurvival signalling and reduced apoptosis in cardiac myocytes. ${ }^{21}$ Similar protection has also been reported in models of cerebral I/R injury. ${ }^{30,138}$ In this setting, parameters of vascular inflammation such as rolling and adhesion of platelets and leukocytes were suppressed and oedema and blood-brain barrier function were improved. Strikingly, focal transient ischaemia strongly
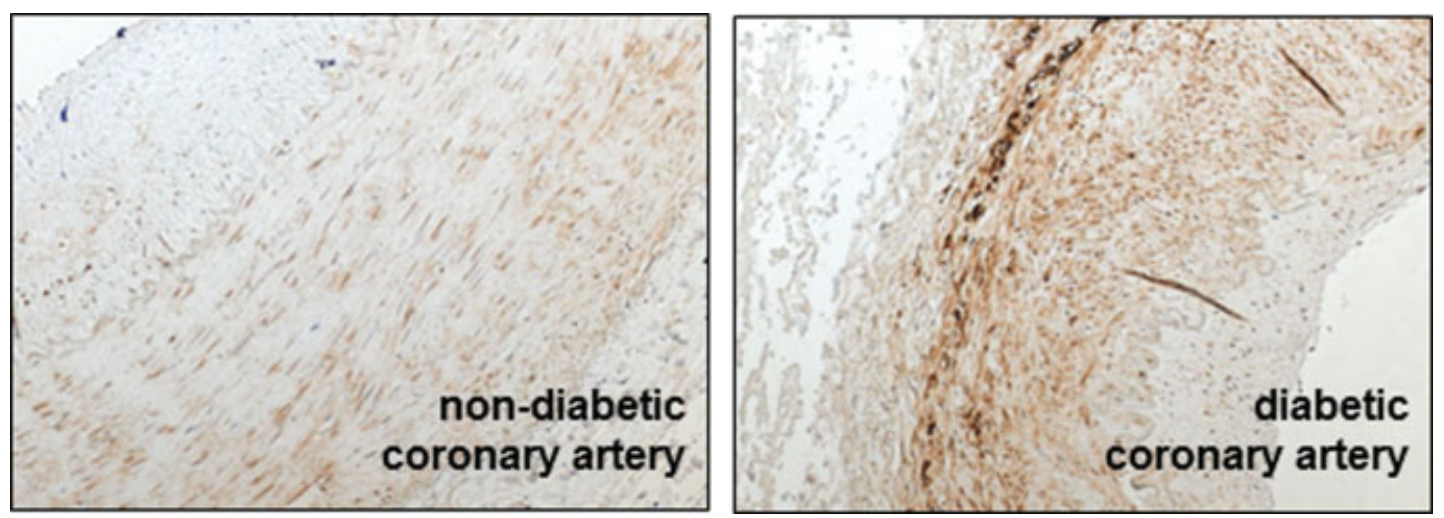

Fig. 2 Increased PAR-4 abundance in human diabetic coronary artery. Representative immunohistochemistry (unpublished, $n=3$ ) for PAR-4 (brown) in tunica media of human non-diabetic and diabetic coronary artery sections (patients described in Shpacovitch et al ${ }^{23}$ ). PAR-4 was visualized with primary antibody ab66103 (1:50, Abcam, Cambridge, UK) and secondary goat anti-rabbit antibody sc-2004 (Santa Cruz Biotechnology, Santa Cruz, CA) plus DAB Substrate Kit (Zytomed Systems). 
mouse aorta

PAR-4 abundance 3 weeks \pm STZ
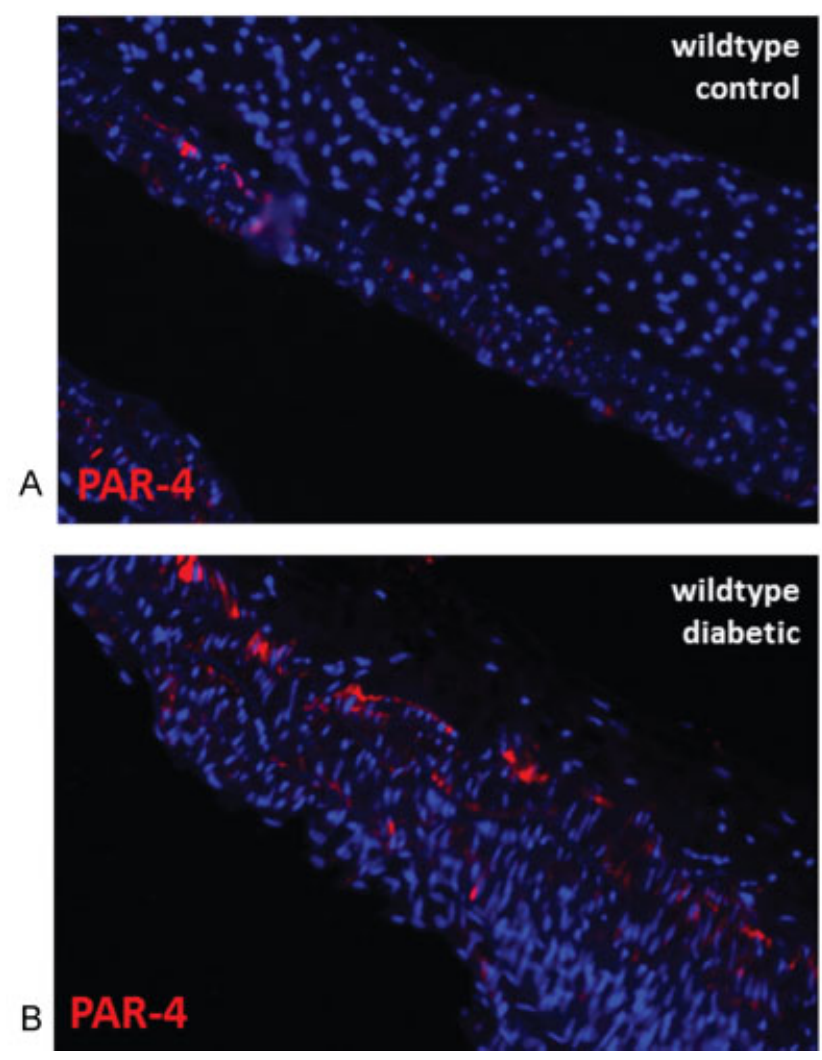

\section{mouse carotid artery Neointima 4 weeks post ligation}
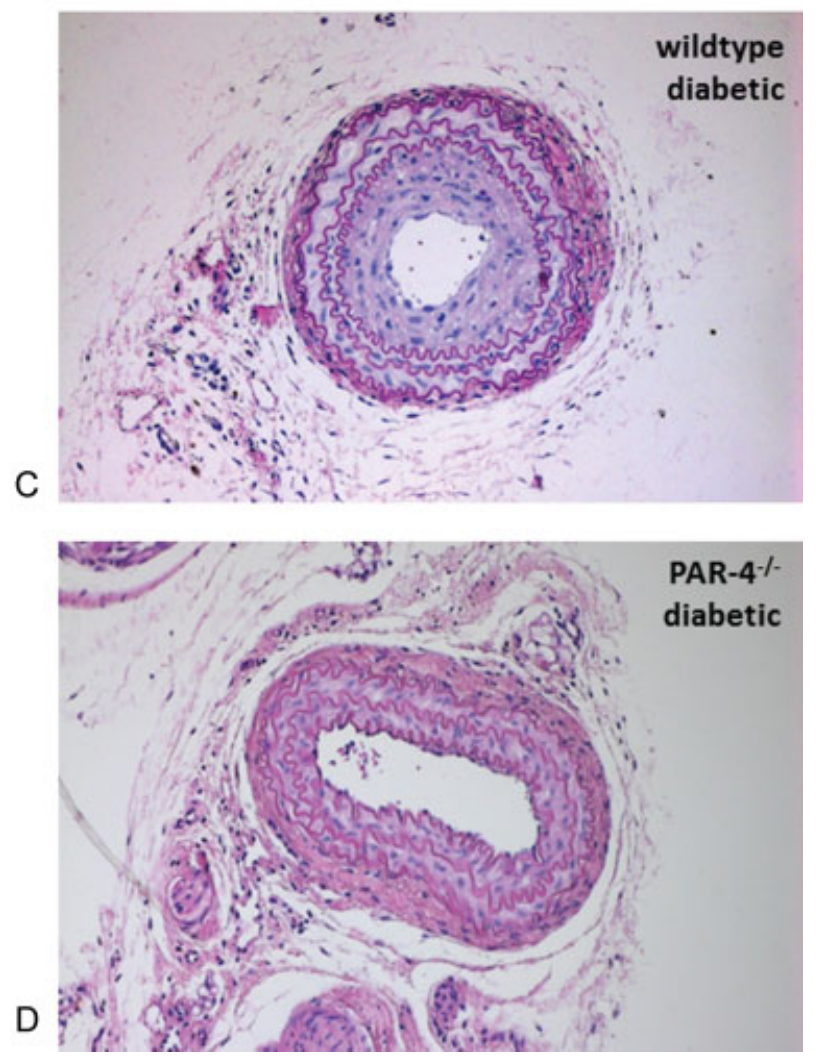

Fig. 3 Diabetes augments vascular PAR-4 expression and neointimal hyperplasia after carotid artery ligation in mice. Representative PAR-4 immunofluorescence (red) in aorta of non-diabetic (a) and diabetic mice (b), 3 weeks after treatment \pm streptozotocin (200 $\times$ magnification). Neointimal hyperplasia of carotid arteries from diabetic (streptozotocin) wildtype (c) and PAR-4 ${ }^{-1-}$ mice (d), 4 weeks after ligation, visualized by haematoxylin and eosin (H\&E) staining. Representative H\&E sections taken $500 \mu$ m proximal to the ligation site $(100 \times$ magnification). All $n=6$, unpublished images (AF); detailed procedures described in Shpacovitch et al. ${ }^{23}$

increased cerebral PAR-4 expression, while other PAR were only moderately and transiently influenced or, in the case or PAR-1, significantly downregulated. ${ }^{138}$ This observation is in keeping with a specialized role of PAR-4 in settings of inflammation-associated injury and remodelling, at least in mouse models. Interestingly, certain single nucleotide polymorphisms in human PAR-4 have been associated with perioperative myocardial injury, with patients homozygous for the rs773857 risk allele showing increased platelet count and hyperactivity. ${ }^{139,140}$ Thus, PAR-4 may also emerge as a target for strategies to limit clinical $\mathrm{I} / \mathrm{R}$ injury.

\section{Therapeutic Targeting of PAR-4}

The prototypical thrombin receptor PAR- 1 has been the focus of intense research as a therapeutic target for novel anti-thrombotic drugs. PAR-4, by contrast, was for a long time seen as a mere co-factor for PAR-1 or 'back-up' receptor, with functional relevance only at high thrombin levels. Accordingly, PAR-4deficient mice show no overt phenotype beyond prolonged bleeding time and protection from experimental thromboembolism. ${ }^{141}$ Although PAR-4 responds to thrombin with an about 100 -fold lower potency than PAR-1 $\left(\mathrm{EC}_{50}=5 \mathrm{nM}\right.$ vs.
$0.05 \mathrm{nM}),{ }^{16,142}$ both receptors have the capacity to fully activate platelets ${ }^{2,143}$ and appear to play equally critical but distinct roles in platelet activation. By virtue of its slower on/off kinetics, PAR-4 ensures a sustained calcium signalling response and, according to a recent study, is more important than PAR-1 for the procoagulant effect of thrombin on platelets during prolonged thrombus formation. ${ }^{144,145}$ PAR-4 has thus emerged as a promising candidate target for new anti-thrombotic therapies. This approach could be particularly suited in patients in whom complete thrombin inhibition or selective PAR1 blockade leads to excessive bleeding or other undesired effects, as well as in patients with myocardial damage or diabetes who display heightened platelet PAR-4 reactivity. Currently, the development of selective PAR-4 antagonists is still in its infancy. Available to date are the trans-cinnamoylYPGKF-amide (tc-Y-NH${ }_{2}$ ), based on the PAR-4 tethered ligand sequence, the pepducin P4pal10 (palmitoyl-SGRRYGHALRamide), a cell-penetrating lipopeptide and YD-3, a non-peptide indole compound. ${ }^{146,147}$ Only one PAR4 inhibitor, BMS986120 , has been applied in humans (clinicaltrials.gov registry number NCT02208882) ) $^{148}$ and will be discussed further on.

Another consideration with the use of selective PAR-1 blockers is the central role of the receptor in endothelial barrier 


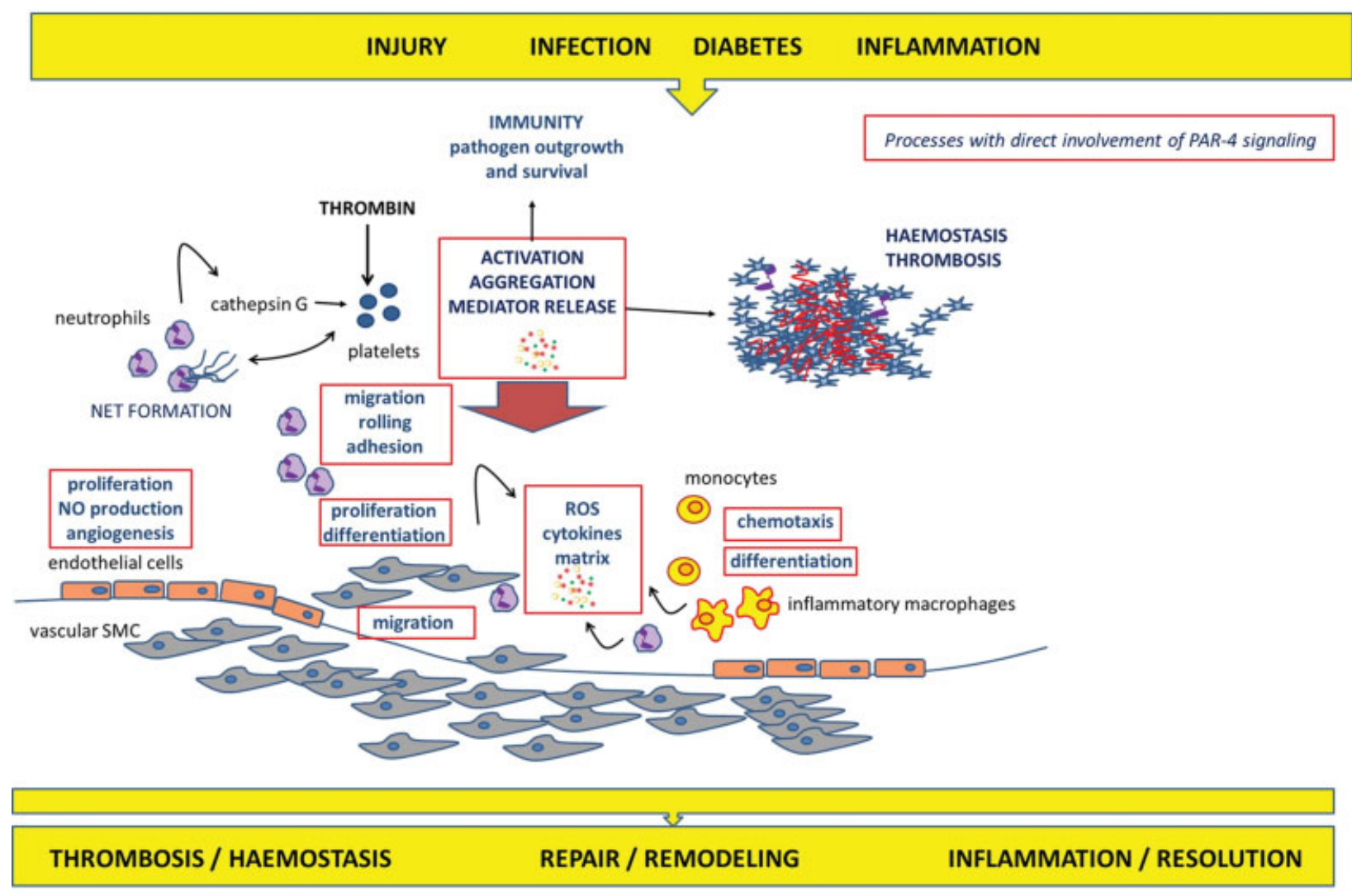

Fig. 4 Simplified schematic of PAR-4 contribution to thromboinflammation. In settings of injury and stress, such as diabetes, inflammation and infection, generation of the primary PAR-4 activators thrombin and cathepsin $G$ is enhanced, leading to augmented (PAR-4-mediated) platelet activation. This triggers platelet activation and aggregation, culminating in the haemostatic response and, depending on context, thrombosis. Cross-talk with neutrophils and induction of NETosis further amplifies this. Release of platelet-derived mediators such as thrombin, PF4, gremlin-1, reactive oxygen species, various growth factors, adhesion molecules, sphingolipids and others, moreover, promotes cellular signalling responses that support immune defence as well as vascular repair and remodelling, inflammation and resolution. Many of these effects, specifically neutrophil and monocyte recruitment and inflammatory/oxidative mediator release, as well as vascular smooth muscle cells (SMC) proliferation, migration, differentiation and release of cytokines and inflammatory/oxidative mediator release, are directly mediated through PAR-4 expression, which is dynamically upregulated in numerous cell types by injury, diabetic or inflammatory stress, or infection.

integrity and protection, in response to aPC. Protein $\mathrm{C}$ is activated to aPC via cleavage by the thrombin-thrombomodulin complex, which then elicits a combination of anti-coagulant and cytoprotective, anti-inflammatory cell signalling responses. The latter require engagement of the EPCR with secondary activation of PAR-1, while the anti-coagulant action of aPC depends on proteolytic inactivation of coagulation factor Va. ${ }^{149,150}$

One clinical condition in which aPC is of particular importance is sepsis, a systemic host response to microbial infection associated with a high mortality, due to the mutual potentiation of inflammation and coagulation. Sepsis leads to a rapid decline in PC, and low levels of PC correlate with poor prognosis. Recombinant aPC was successfully evaluated some 16 years ago (PROWESS Study) and approved for adult severe sepsis. However, the drug was subsequently withdrawn from the market after failing to show benefit in paediatric sepsis, non-severe adult sepsis and acute lung injury in follow-up trials (APACHE II, RESOLVE, PROWESS-SHOCK). This might in part be due to dosing. Clinically used aPC doses result in plasma concentrations that are still much lower than endogenous PC levels, and which may be inadequate to compete with endo- genous PC for EPCR binding. An upper dosing limit is, however, set by adverse bleeding due to the strong anti-coagulant response to aPC. This dilemma, and which patients will yet benefit from aPC therapy, has recently been discussed in detail elsewhere. ${ }^{151,152}$ How PAR-4 fits in this picture remains to be defined. In a canine model of bacterial infection and inflammation, platelet activation in response to PAR-4 agonists was disturbed, although not at the level of receptor expression. ${ }^{153}$ In a mouse endotoxinemia model, prasugrel inhibited PAR-4-dependent platelet activation and platelet-leukocyte interactions. ${ }^{154}$ However, other mouse studies failed to support an important role for any PARs in endotoxemia; in fact, PAR- $4^{-1-}$ mice showed decreased survival. ${ }^{155,156}$

Besides its designated role in the endothelium, EPCR is also expressed in human vascular SMC, where it positively modulates the mitogenic actions of thrombin in the presence of aPC. ${ }^{46}$ This could potentially contribute to local repair processes after injury. Suppression of protective EPCR-dependent functions could conceivably limit the net usefulness of selective PAR- 1 blockers. PAR- 4 by contrast is functionally independent of the aPC/thrombomodulin/EPCR signalling system. The increased functional relevance of PAR-4 in 
thromboinflammatory settings suggests that this receptor in particular may be a candidate to switch away from timely and controlled resolution of inflammation. This feature of PAR-4, together with its relevance at pathological rather than physiological thrombin levels, makes the receptor an attractive target for novel therapies.

\section{Clinical Implications}

Selective PAR-4 blockers will limit thrombin-inducible, PAR1 -independent actions. They, therefore, will not interfere in constitutive thrombin functions mediated through PAR-1, such as the protective effects demonstrated by vorapaxar in PAD patients. Activation of PAR-4 appears to drive thrombin production to a greater extent than PAR-1; ${ }^{121}$ therefore, functional upregulation of PAR-4 in conditions of inflammation or diabetes could explain in part the enhanced prothrombotic risk that occurs in these settings. By extension, selective PAR-4 blockade might be expected to show a greater efficacy and safety in certain patients than inhibition of constitutively expressed PAR-1. PAR-1 antagonism has been evaluated in randomized controlled trials (RCTs) of vorapaxar for the secondary prevention of major adverse cardiovascular events (MACE) in high-risk cardiovascular patients. ${ }^{157,158}$ Although vorapaxar showed enhanced efficacy to reduce MACE compared with dual anti-platelet therapy including acetylic salicylic acid plus clopidogrel, bleeding risk in certain subgroups, in particular in patients with a history of cerebrovascular events, remains a major concern.

Results of a randomized, blinded, placebo-controlled study including in vivo experiments with clopidogrel and the selective PAR-4 antagonist BMS-986120 in monkeys were published recently. ${ }^{159}$ The primary end points were thrombus weight reduction, integrated blood flow and increased bleeding time. This study also comprised in vitro experiments using human blood. Human platelet-rich plasma aggregation in response to gamma-thrombin was fully inhibited in vitro by BMS-986120. In the animal study, BMS-986120 produced dose-dependent, selective and reversible (within 24 hours after last dose) inhibition of platelet aggregation and reduction of thrombus weight without relevant signals on bleeding times. Compared with the long half-life of the PAR-1 antagonist vorapaxar, which inhibits platelets for several weeks after a single loading dose in humans, explaining some of the adverse safety effects in RCTs, the pharmacodynamics of currently evaluated PAR-4 antagonists make the compound attractive in high-risk scenarios for thrombosis and bleeding.

In conclusion, it is tempting to speculate that compared with current, mainly platelet-directed, strategies, selective antagonism of PAR- 4 offers both an effective and safe antithrombotic strategy in the acute thrombotic setting as well as anti-inflammatory strategies to prevent long-term progressive atherosclerotic disease in high-risk cardiovascular patients. Future studies are warranted to better interpret reported variabilities and mechanisms of PAR-4 responses in humans and the pharmacodynamic effects of PAR-4 antagonists.

\section{Financial Support}

A. C. F. was supported by grants from the Deutsche Forschungsgemeinschaft (RO 3921/2-1), the Ernst und Berta Grimmke-Stiftung Düsseldorf (3/09) and the Gesellschaft für Thrombose- und Hämostase-Forschung (Rudolf-Marx Stipend); B. H. R. was supported by the DFG (RA 1714/1-2) and by the Forschungsgruppe Herz-Kreislauf e.V.

\section{References}

1 Witkowski M, Landmesser U, Rauch U. Tissue factor as a link between inflammation and coagulation. Trends Cardiovasc Med 2016;26(04):297-303

2 Kahn ML, Nakanishi-Matsui M, Shapiro MJ, Ishihara H, Coughlin SR. Protease-activated receptors 1 and 4 mediate activation of human platelets by thrombin. J Clin Invest 1999;103(06):879-887

3 Kahn ML, Zheng YW, Huang W, et al. A dual thrombin receptor system for platelet activation. Nature 1998;394(6694):690-694

4 Sambrano GR, Weiss EJ, Zheng YW, Huang W, Coughlin SR. Role of thrombin signalling in platelets in haemostasis and thrombosis. Nature 2001;413(6851):74-78

5 Mihara K, Ramachandran R, Saifeddine M, et al. Thrombinmediated direct activation of proteinase-activated receptor-2: another target for thrombin signaling. Mol Pharmacol 2016; 89(05):606-614

6 Nakanishi-Matsui M, Zheng YW, Sulciner DJ, Weiss EJ, Ludeman MJ, Coughlin SR. PAR3 is a cofactor for PAR4 activation by thrombin. Nature 2000;404(6778):609-613

7 Steinberg SF. The cardiovascular actions of protease-activated receptors. Mol Pharmacol 2005;67(01):2-11

8 Sidhu TS, French SL, Hamilton JR. Differential signaling by protease-activated receptors: implications for therapeutic targeting. Int J Mol Sci 2014;15(04):6169-6183

9 Khan A, Li D, Ibrahim S, Smyth E, Woulfe DS. The physical association of the P2Y12 receptor with PAR4 regulates arrestin-mediated Akt activation. Mol Pharmacol 2014;86:1-11

10 Leger AJ, Jacques SL, Badar J, et al. Blocking the proteaseactivated receptor 1-4 heterodimer in platelet-mediated thrombosis. Circulation 2006;113:1244-54

11 Lin H, Liu AP, Smith TH, Trejo J. Cofactoring and dimerization of proteinase-activated receptors. Pharmacol Rev 2013;65:1198-213

12 McLaughlin JN, Patterson MM, Malik AB. Protease-activated receptor-3 (PAR3) regulates PAR1 signaling by receptor dimerization. Proc Natl Acad Sci USA 2007;104:5662-7

13 Erhardt JA, Toomey JR, Douglas SA, Johns DG. P2X1 stimulation promotes thrombin receptor-mediated platelet aggregation. J Thromb Haemost 2006;4:882-90

14 Bernlochner I, Sibbing D. Thienopyridines and other ADP-receptor antagonists. Handbook Exp Pharmacol 2012:165-98

15 Holinstat M, Voss B, Bilodeau ML, et al. PAR4, but not PAR1, signals human platelet aggregation via $\mathrm{Ca} 2+$ mobilization and synergistic P2Y12 receptor activation. J Biol Chem 2006;281:26665-74

16 Shapiro MJ, Weiss EJ, Faruqi TR, Coughlin SR. Protease-activated receptors 1 and 4 are shut off with distinct kinetics after activation by thrombin. J Biol Chem 2000;275:25216-21

17 Badr Eslam R, Lang IM, Koppensteiner R, et al. Residual platelet activation through protease-activated receptors (PAR)-1 and -4 in patients on P2Y12 inhibitors. Int J Cardiol 2013;168:403-6

18 Schrör K, Bretschneider E, Fischer K, et al. Thrombin receptors in vascular smooth muscle cells - function and regulation by vasodilatory prostaglandins. Thromb Haemost 2010;103:884-90

19 Brummel KE, Paradis SG, Butenas S, Mann KG. Thrombin functions during tissue factor-induced blood coagulation. Blood 2002;100:148-52

20 Rosenkranz AC, Schror K, Rauch BH. Direct inhibitors of thrombin and factor $\mathrm{Xa}$ attenuate clot-induced mitogenesis and 
inflammatory gene expression in human vascular smooth muscle cells. Thromb Haemost 2011;106:561-2

21 Kolpakov MA, Rafiq K, Guo X, et al. Protease-activated receptor 4 deficiency offers cardioprotection after acute ischemia reperfusion injury. J Mol Cell Cardiol 2016;90:21-9

22 French SL, Hamilton JR. Protease-activated receptor 4: from structure to function and back again. Br J Pharmacol 2016

23 Pavic G, Grandoch M, Dangwal S, et al. Thrombin receptor protease-activated receptor 4 is a key regulator of exaggerated intimal thickening in diabetes mellitus. Circulation 2014;130:1700-11

24 Wygrecka M, Didiasova M, Berscheid S, et al. Protease-activated receptors (PAR)-1 and -3 drive epithelial-mesenchymal transition of alveolar epithelial cells - potential role in lung fibrosis. Thromb Haemost 2013;110:295-307

25 Tiburcio M, Costa SM, M DEFD, Schmitt FC, Longatto Filho A. Characterization of PAR1 and FGFR1 expression in invasive breast carcinomas: Prognostic significance. Oncol Lett 2012;4:647-57

26 Snead AN, Insel PA. Defining the cellular repertoire of GPCRs identifies a profibrotic role for the most highly expressed receptor, protease-activated receptor 1 , in cardiac fibroblasts. FASEB J 2012;26(11):4540-7

27 Han N, Jin K, He K, Cao J, Teng L. Protease-activated receptors in cancer: A systematic review. Oncol Lett 2011;2:599-608

28 Dabek M, Ferrier L, Annahazi A, et al. Intracolonic infusion of fecal supernatants from ulcerative colitis patients triggers altered permeability and inflammation in mice: role of cathepsin $\mathrm{G}$ and protease-activated receptor-4. Inflamm Bowel Dis 2011; 17:1409-14

29 Antoniak S, Pawlinski R, Mackman N. Protease-activated receptors and myocardial infarction. IUBMB Life 2011;63:383-9

30 Mao Y, Zhang M, Tuma RF, Kunapuli SP. Deficiency of PAR4 attenuates cerebral ischemia/reperfusion injury in mice. J Cereb Blood Flow Metab 2010;30:1044-52

31 Shah R. Protease-activated receptors in cardiovascular health and diseases. Am Heart J 2009;157:253-62

32 Shpacovitch V, Feld M, Hollenberg MD, Luger TA, Steinhoff M. Role of protease-activated receptors in inflammatory responses, innate and adaptive immunity. J LeukocBiol 2008;83:1309-22

33 Leger AJ, Covic L, Kuliopulos A. Protease-activated receptors in cardiovascular diseases. Circulation 2006;114:1070-7

34 Griffin JH, Zlokovic BV, Mosnier LO. Activated protein C: biased for translation. Blood 2015;125:2898-907

35 Mutch NJ, Robbie LA, Booth NA. Human thrombi contain an abundance of active thrombin. Thromb Haemost 2001;86:1028-34

36 Bar-Shavit R, Eldor A, Vlodavsky I. Binding of thrombin to subendothelial extracellular matrix. Protection and expression of functional properties. J Clin Invest 1989;84:1096-104

37 Bonaca MP, Scirica BM, Creager MA, et al. Vorapaxar in patients with peripheral artery disease: results from TRA2P-TIMI 50. Circulation 2013;127:1522-9, 9e1-6

38 Borissoff JI, Spronk HM, Heeneman S, ten Cate H. Is thrombin a key player in the 'coagulation-atherogenesis' maze? Cardiovasc Res 2009;82:392-403

39 Coughlin SR. Protease-activated receptors in vascular biology. Thromb Haemost 2001;86:298-307

40 Fisslthaler B, Schini-Kerth VB, Fleming I, Busse R. Thrombin receptor expression is increased by angiotensin II in cultured and native vascular smooth muscle cells. Cardiovasc Res 1998;38:263-71

41 Fukunaga R, Hirano K, Hirano M, et al. Upregulation of proteinase-activated receptors and hypercontractile responses precede development of arterial lesions after balloon injury. Am J Physiol Heart Circ Physiol 2006;291:H2388-95

42 Hirano K. The Roles of Proteinase-Activated Receptors in the Vascular Physiology and Pathophysiology. Arterioscler Thromb Vasc Biol 2006

43 Napoli C, de Nigris F, Wallace JL, et al. Evidence that protease activated receptor 2 expression is enhanced in human coronary atherosclerotic lesions. J Clin Pathol 2004;57:513-6
44 Bretschneider E, Kaufmann R, Braun M, et al. Evidence for functionally active protease-activated receptor-4 (PAR-4) in human vascular smooth muscle cells. Br J Pharmacol 2001; 132:1441-6

45 Bretschneider E, Spanbroek R, Lotzer K, Habenicht AJ, Schrör K. Evidence for functionally active protease-activated receptor-3 (PAR-3) in human vascular smooth muscle cells. Thromb Haemost 2003;90:704-9

46 Bretschneider E, Uzonyi B, Weber AA, et al. Human vascular smooth muscle cells express functionally active endothelial cell protein C receptor. Circ Res 2007;100:255-62

47 Bretschneider E, Wittpoth M, Weber AA, Glusa E, Schrör K. Thrombin but not thrombin receptor activating peptide is mitogenic for coronary artery smooth muscle cells. Thromb Res 1997;87:493-7

48 Dangwal S, Rauch BH, Gensch T, et al. High glucose enhances thrombin responses via protease-activated receptor- 4 in human vascular smooth muscle cells. Arterioscler Thromb Vasc Biol 2011;31:624-33

49 Mahajan SG, Fender AC, Meyer-Kirchrath J, et al. A novel function of FoxO transcription factors in thrombin-stimulated vascular smooth muscle cell proliferation. Thromb Haemost 2012;108:148-58

50 Pape R, Rauch BH, Rosenkranz AC, Kaber G, Schrör K. Transcriptional Inhibition of Protease-Activated Receptor-1 Expression by Prostacyclin in Human Vascular Smooth Muscle Cells. Arterioscler Thromb Vasc Biol2007

51 Rabausch K, Bretschneider E, Sarbia M, et al. Regulation of thrombomodulin expression in human vascular smooth muscle cells by COX-2-derived prostaglandins. Circ Res 2005;96:e1-6

52 Rosenkranz AC, Rauch BH, Doller A, et al. Regulation of human vascular protease-activated receptor-3 through mRNA stabilization and the transcription factor nuclear factor of activated $\mathrm{T}$ Cells (NFAT). Mol Pharmacol 2011;80:337-44

53 Rosenkranz AC, Rauch BH, Freidel K, Schrör K. Regulation of protease-activated receptor- 1 by vasodilatory prostaglandins via NFAT. Cardiovasc Res 2009;83:778-84

54 Aman M, Hirano M, Kanaide H, Hirano K. Upregulation of Proteinase-Activated Receptor-2 and Increased Response to Trypsin in Endothelial Cells after Exposure to Oxidative Stress in Rat Aortas. J Vasc Res 2010;47:494-506

55 Damiano BP, D’Andrea MR, de Garavilla L, Cheung WM, AndradeGordon P. Increased expression of protease activated receptor-2 (PAR-2) in balloon-injured rat carotid artery. Thromb Haemost 1999;81:808-14

56 Hamilton JR, Frauman AG, Cocks TM. Increased expression of protease-activated receptor-2 (PAR2) and PAR4 in human coronary artery by inflammatory stimuli unveils endothelium-dependent relaxations to PAR2 and PAR4 agonists. Circ Res 2001;89:92-8

57 Jesmin S, Gando S, Zaedi S, Sakuraya F. Differential expression, time course and distribution of four PARs in rats with endotoxininduced acute lung injury. Inflammation 2007;30:14-27

58 Ritchie E, Saka M, Mackenzie C, et al. Cytokine upregulation of proteinase-activated-receptors 2 and 4 expression mediated by p38 MAP kinase and inhibitory kappa B kinase beta in human endothelial cells. Br J Pharmacol 2007;150:1044-54

59 Roviezzo F, Bucci M, Brancaleone V, et al. Proteinase-activated receptor-2 mediates arterial vasodilation in diabetes. Arterioscler Thromb Vasc Biol 2005;25:2349-54

60 Nelken NA, Soifer SJ, O'Keefe J, et al. Thrombin receptor expression in normal and atherosclerotic human arteries. J Clin Invest 1992;90:1614-21

61 Mahajan-Thakur S, Sostmann BD, Fender AC, et al. Sphingosine1-phosphate induces thrombin receptor PAR-4 expression to enhance cell migration and COX-2 formation in human monocytes. J Leukoc Biol 2014;96:611-8

62 Jobi K, Rauch BH, Dangwal S, et al. Redox regulation of human protease-activated receptor- 2 by activated factor X. Free Radic Biol Med 2011;51:1758-64 
63 Hamilton JR, Moffatt JD, Frauman AG, Cocks TM. Protease-activated receptor (PAR) 1 but not PAR2 or PAR4 mediates endothelium-dependent relaxation to thrombin and trypsin in human pulmonary arteries. J Cardiovasc Pharmacol 2001;38:108-19

64 Kahn ML, Hammes SR, Botka C, Coughlin SR. Gene and locus structure and chromosomal localization of the protease-activated receptor gene family. J Biol Chem 1998;273:23290-6

65 Pullmann R Jr., Juhaszova M, Lopez de Silanes I, et al. Enhanced proliferation of cultured human vascular smooth muscle cells linked to increased function of RNA-binding protein HuR. J Biol Chem 2005;280:22819-26

66 Sedlyarov V, Fallmann J, Ebner F, et al. Tristetraprolin binding site atlas in the macrophage transcriptome reveals a switch for inflammation resolution. Mol Syst Biol 2016;12:868

67 Kim Y, Noren Hooten N, Dluzen DF, et al. Posttranscriptional Regulation of the Inflammatory Marker C-Reactive Protein by the RNA-Binding Protein HuR and MicroRNA 637. Mol Cell Biol 2015; 35:4212-21

68 Dong R, Lu JG, Wang Q, et al. Stabilization of Snail by HuR in the process of hydrogen peroxide induced cell migration. Biochem Biophys Res Commun 2007;356:318-21

69 Doller A, Akool el S, Huwiler A, et al. Posttranslational modification of the AU-rich element binding protein HuR by protein kinase Cdelta elicits angiotensin II-induced stabilization and nuclear export of cyclooxygenase 2 mRNA. Mol Cell Biol 2008; 28:2608-25

70 Morris BJ, Adams DJ, Beveridge DJ, et al. cAMP controls human renin mRNA stability via specific RNA-binding proteins. Acta Physiol Scand 2004;181:369-73

71 Belton O, Byrne D, Kearney D, Leahy A, Fitzgerald DJ. Cyclooxygenase-1 and -2-dependent prostacyclin formation in patients with atherosclerosis. Circulation 2000;102:840-5

72 Bishop-Bailey D, Pepper JR, Larkin SW, Mitchell JA. Differential induction of cyclooxygenase- 2 in human arterial and venous smooth muscle: role of endogenous prostanoids. Arterioscler Thromb Vasc Biol 1998;18:1655-61

73 Rimarachin JA, Jacobson JA, Szabo P, et al. Regulation of cyclooxygenase-2 expression in aortic smooth muscle cells. Arterioscler Thromb 1994;14:1021-31

74 Syeda F, Grosjean J, Houliston RA, et al. Cyclooxygenase-2 induction and prostacyclin release by protease-activated receptors in endothelial cells require cooperation between mitogenactivated protein kinase and NF-kappaB pathways. J Biol Chem 2006;281:11792-804

75 Rullier A, Senant N, Kisiel W, et al. Expression of proteaseactivated receptors and tissue factor in human liver. Virchows Arch 2006;448:46-51

76 Mende K, Reifart J, Rosentreter D, et al. Targeting platelet migration in the postischemic liver by blocking protease-activated receptor 4. Transplantation 2014;97:154-60

77 Li X, Syrovets T, Paskas S, Laumonnier Y, Simmet T. Mature dendritic cells express functional thrombin receptors triggering chemotaxis and CCL18/pulmonary and activation-regulated chemokine induction. J Immunol 2008;181:1215-23

78 Houle S, Papez MD, Ferazzini M, Hollenberg MD, Vergnolle N. Neutrophils and the kallikrein-kinin system in proteinase-activated receptor 4-mediated inflammation in rodents. Br J Pharmacol 2005;146:670-8

79 Hirano K, Nomoto N, Hirano M, et al. Distinct Ca2+ requirement for NO production between proteinase-activated receptor 1 and 4 (PAR1 and PAR4) in vascular endothelial cells. J Pharmacol Exp Ther 2007;322:668-77

80 Kaplan ZS, Zarpellon A, Alwis I, et al. Thrombin-dependent intravascular leukocyte trafficking regulated by fibrin and the platelet receptors GPIb and PAR4. Nat Commun 2015;6:7835

81 Fu Q, Cheng J, Gao Y, et al. Protease-activated receptor 4: a critical participator in inflammatory response. Inflammation 2015; 38:886-95
82 Jani PK, Schwaner E, Kajdacsi E, et al. Complement MASP-1 enhances adhesion between endothelial cells and neutrophils by up-regulating E-selectin expression. Mol Immunol 2016;75:38-47

83 Megyeri M, Mako V, Beinrohr L, et al. . Complement protease MASP-1 activates human endothelial cells: PAR4 activation is a link between complement and endothelial function. J Immunol 2009;183:3409-16

84 Sambrano GR, Huang W, Faruqi T, et al. Cathepsin G activates protease-activated receptor-4 in human platelets. J Biol Chem 2000;275:6819-23

85 Wu CC, Hwang TL, Liao CH, et al. Selective inhibition of proteaseactivated receptor 4-dependent platelet activation by YD-3. Thromb Haemost 2002;87:1026-33

86 Ramachandran R, Sadofsky LR, Xiao Y, et al. Inflammatory mediators modulate thrombin and cathepsin- $G$ signaling in human bronchial fibroblasts by inducing expression of proteinase-activated receptor-4. Am J Physiol 2007;292:L788-98

87 Baltus T, von Hundelshausen P, Mause SF, et al. Differential and additive effects of platelet-derived chemokines on monocyte arrest on inflamed endothelium under flow conditions. J Leukoc Biol 2005;78:435-41

88 Mahajan-Thakur S, Bohm A, Jedlitschky G, Schror K, Rauch BH. Sphingosine-1-Phosphate and Its Receptors: A Mutual Link between Blood Coagulation and Inflammation. Mediators Inflamm 2015;2015:831059

89 Rauch BH. Sphingosine 1-phosphate as a link between blood coagulation and inflammation. Cell Physiol Biochem 2014; 34:185-96

90 Bar-Shavit R, Kahn A, Fenton JW, Wilner GD. Chemotactic response of monocytes to thrombin. J Cell Biol 1983;96:282-5

91 Soslau G, Goldenberg SJ, Class R, Jameson B. Differential activation and inhibition of human platelet thrombin receptors by structurally distinct alpha-, beta- and gamma-thrombin. Platelets 2004;15:155-66

92 Hechler B, Gachet C. Purinergic Receptors in Thrombosis and Inflammation. Arterioscler Thromb Vasc Biol 2015;35:2307-15

93 Nylander S, Schulz R. Effects of P2Y12 receptor antagonists beyond platelet inhibition-comparison of ticagrelor with thienopyridines. Br J Pharmacol 2016;173:1163-78

94 Willerson JT, Cable G, Yeh ET. PROCLAIM: pilot study to examine the effects of clopidogrel on inflammatory markers in patients with metabolic syndrome receiving low-dose aspirin. Texas Heart Inst J 2009;36:530-9

95 Kalantzi KI, Dimitriou AA, Milionis HJ, Goudevenos IA, Tselepis AD. Clopidogrel differentially affects platelet-mediated thrombosis and inflammatory response in patients with acute coronary syndromes. J Thromb Haemost 2011;9:875-8

96 Antonino MJ, Mahla E, Bliden KP, Tantry US, Gurbel PA. Effect of long-term clopidogrel treatment on platelet function and inflammation in patients undergoing coronary arterial stenting. Am J Cardiol 2009;103:1546-50

97 Steinhubl SR, Badimon JJ, Bhatt DL, Herbert JM, Luscher TF. Clinical evidence for anti-inflammatory effects of antiplatelet therapy in patients with atherothrombotic disease. Vasc Med 2007;12:113-22

98 Klinkhardt U, Graff J, Harder S. Clopidogrel, but not abciximab, reduces platelet leukocyte conjugates and P-selectin expression in a human ex vivo in vitro model. Clin Pharm Ther 2002; 71:176-85

99 Gachet C. P2Y(12) receptors in platelets and other hematopoietic and non-hematopoietic cells. Purin Signal 2012;8:609-19

100 Shanker G, Kontos JL, Eckman DM, Wesley-Farrington D, Sane DC. Nicotine upregulates the expression of P2Y12 on vascular cells and megakaryoblasts. J Thromb Thrombolysis 2006;22:213-20

101 Wihlborg AK, Wang L, Braun OO, et al. ADP receptor P2Y12 is expressed in vascular smooth muscle cells and stimulates contraction in human blood vessels. Arterioscler Thromb Vasc Biol $2004 ; 24: 1810-5$ 
102 Rauch BH, Rosenkranz AC, Ermler S, et al. Regulation of functionally active P2Y12 ADP receptors by thrombin in human smooth muscle cells and the presence of P2Y12 in carotid artery lesions. Arterioscler Thromb Vasc Biol 2010;30:2434-42

103 Li D, D’Angelo L, Chavez M, Woulfe DS. Arrestin-2 differentially regulates PAR4 and ADP receptor signaling in platelets. J Biol Chem 2011;286:3805-14

104 Yun LW, Decarlo AA, Hunter N. Blockade of protease-activated receptors on $T$ cells correlates with altered proteolysis of $C D 27$ by gingipains of Porphyromonas gingivalis. Clin Exp Immunol 2007; 150:217-29

105 Gomides LF, Lima OC, Matos NA, et al. Blockade of proteinaseactivated receptor 4 inhibits neutrophil recruitment in experimental inflammation in mice. Inflamm Res 2014;63:935-41

106 Slofstra SH, Bijlsma MF, Groot AP, et al. Protease-activated receptor- 4 inhibition protects from multiorgan failure in a murine model of systemic inflammation. Blood 2007; $110: 3176-82$

107 Li T, Wang H, He S. Induction of interleukin-6 release from monocytes by serine proteinases and its potential mechanisms. Scand J Immunol 2006;64:10-6

108 Vergnolle N, Derian CK, D'Andrea MR, Steinhoff M, AndradeGordon P. Characterization of thrombin-induced leukocyte rolling and adherence: a potential proinflammatory role for proteinase-activated receptor-4. J Immunol 2002;169:1467-73

109 Herter JM, Rossaint J, Zarbock A. Platelets in inflammation and immunity. J Thromb Haemost 2014;12:1764-75

110 Jenne CN, Urrutia R, Kubes P. Platelets: bridging hemostasis, inflammation, and immunity. Int J Lab Hematol 2013;35:254-61

111 Koenen RR. The prowess of platelets in immunity and inflammation. Thromb Haemost 2016;116:605-12

112 Mantovani A, Garlanda C. Platelet-macrophage partnership in innate immunity and inflammation. Nat Immunol 2013; 14:768-70

113 Kraemer BF, Campbell RA, Schwertz H, et al. Novel anti-bacterial activities of beta-defensin 1 in human platelets: suppression of pathogen growth and signaling of neutrophil extracellular trap formation. PLoS Pathog 2011; 7:e1002355

114 Perkhofer S, Kainzner B, Kehrel BE, et al. Potential antifungal effects of human platelets against zygomycetes in vitro. J Infect Dis 2009;200:1176-9

115 Perkhofer S, Kehrel BE, Dierich MP, et al. Human platelets attenuate Aspergillus species via granule-dependent mechanisms. J Infect Dis 2008;198:1243-6

116 Thomas MR, Storey RF. Effect of P2Y12 inhibitors on inflammation and immunity. Thromb Haemost 2015;114:490-7

117 Storey RF, James SK, Siegbahn A, et al. Lower mortality following pulmonary adverse events and sepsis with ticagrelor compared to clopidogrel in the PLATO study. Platelets 2014;25:517-25

118 Blasco-Colmenares E, Perl TM, Guallar E, et al. Aspirin plus clopidogrel and risk of infection after coronary artery bypass surgery. Arch Intern Med 2009;169:788-96

119 van Holten TC, Bleijerveld OB, Wijten P, et al. Quantitative proteomics analysis reveals similar release profiles following specific PAR-1 or PAR-4 stimulation of platelets. Cardiovasc Res 2014;103:140-6

120 Falker K, Haglund L, Gunnarsson P, et al. Protease-activated receptor 1 (PAR1) signalling desensitization is counteracted via PAR4 signalling in human platelets. Biochem J 2011; 436:469-80

121 Duvernay M, Young S, Gailani D, Schoenecker J, Hamm HE. Protease-activated receptor (PAR) 1 and PAR4 differentially regulate factor $\mathrm{V}$ expression from human platelets. Mol Pharmacol 2013;83:781-92

122 Chatterjee M, Huang Z, Zhang W, et al. Distinct platelet packaging, release, and surface expression of proangiogenic and antiangiogenic factors on different platelet stimuli. Blood 2011; 117:3907-11
123 Chatterjee M, Behrendt A, Schmid M, et al. Platelets as a novel source of Gremlin-1: Implications for thromboinflammation. Thromb Haemost 2017;117:311-24

124 de Stoppelaar SF, Van't Veer C, van den Boogaard FE, et al. Protease activated receptor 4 limits bacterial growth and lung pathology during late stage Streptococcus pneumoniae induced pneumonia in mice. Thromb Haemost 2013;110:582-92

125 Gleissner CA, Shaked I, Erbel C, et al. CXCL4 downregulates the atheroprotective hemoglobin receptor CD163 in human macrophages. Circ Res 2010;106:203-11

126 Gleissner CA. Macrophage Phenotype Modulation by CXCL4 in Atherosclerosis. Front Physiol 2012;3:1

127 Bansilal S, Farkouh ME, Fuster V. Role of insulin resistance and hyperglycemia in the development of atherosclerosis. Am J Cardiol 2007;99:6B-14B

128 Beckman JA, Creager MA, Libby P. Diabetes and atherosclerosis: epidemiology, pathophysiology, and management. JAMA 2002; 287:2570-81

129 Ceriello A. Postprandial hyperglycemia and diabetes complications: is it time to treat? Diabetes 2005;54:1-7

130 Das Evcimen N, King GL. The role of protein kinase C activation and the vascular complications of diabetes. Pharmacol Res 2007; 55:498-510

131 Carr ME. Diabetes mellitus: a hypercoagulable state. J Diabetes Complications 2001;15:44-54

132 Ceriello A, Giacomello R, Stel G, et al. Hyperglycemia-induced thrombin formation in diabetes. The possible role of oxidative stress. Diabetes 1995;44:924-8

133 Stone KE, Chiquette E, Chilton RJ. Diabetic endovascular disease: role of coronary artery revascularization. Am J Cardiol 2007; 99:105B-12B

134 Undas A, Wiek I, Stepien E, Zmudka K, Tracz W. Hyperglycemia is associated with enhanced thrombin formation, platelet activation, and fibrin clot resistance to lysis in patients with acute coronary syndrome. Diab Care 2008;31:1590-5

135 Vaidyula VR, Rao AK, Mozzoli M, et al. Effects of hyperglycemia and hyperinsulinemia on circulating tissue factor procoagulant activity and platelet CD40 ligand. Diabetes 2006;55:202-8

136 Blaas I, Heinz K, Wurtinger P, et al. Vein graft thrombi, a niche for smooth muscle cell colonization - a hypothesis to explain the asymmetry of intimal hyperplasia. J Thromb Haemost 2016; 14:1095-104

137 Stolla MC, Li D, Lu L, Woulfe DS. Enhanced platelet activity and thrombosis in a murine model of type I diabetes are partially insulin-like growth factor 1-dependent and phosphoinositide 3kinase-dependent. J Thromb Haemostasis 2013;11:919-29

138 Rohatgi T, Henrich-Noack P, Sedehizade F, et al. Transient focal ischemia in rat brain differentially regulates mRNA expression of protease-activated receptors 1 to 4. J Neurosci Res 2004; 75:273-9

139 Muehlschlegel JD, Perry TE, Liu KY, et al. Polymorphism in the protease-activated receptor-4 gene region associates with platelet activation and perioperative myocardial injury. Am J Haematol 2012;87:161-6

140 Edelstein LC, Simon LM, Lindsay CR, et al. Common variants in the human platelet PAR4 thrombin receptor alter platelet function and differ by race. Blood 2014;124:3450-8

141 Hamilton JR, Cornelissen I, Coughlin SR. Impaired hemostasis and protection against thrombosis in protease-activated receptor 4-deficient mice is due to lack of thrombin signaling in platelets. J Thromb Haemostasis 2004;2:1429-35

142 Sabri A, Muske G, Zhang H, et al. Signaling properties and functions of two distinct cardiomyocyte protease-activated receptors. Circ Res 2000;86:1054-61

143 Coughlin SR. Thrombin signalling and protease-activated receptors. Nature 2000;407:258-64

144 French SL, Arthur JF, Lee H, et al. Inhibition of protease-activated receptor 4 impairs platelet procoagulant activity during 
thrombus formation in human blood. J Thromb Haemost 2016; $14: 1642-54$

145 Lindahl TL, Macwan AS, Ramstrom S. Protease-activated receptor 4 is more important than protease-activated receptor 1 for the thrombin-induced procoagulant effect on platelets. J Thromb Haemost 2016;14:1639-41

146 Chen HS, Kuo SC, Teng CM, et al. Synthesis and antiplatelet activity of ethyl 4-(1-benzyl-1H-indazol-3-yl)benzoate (YD-3) derivatives. Bioorg Med Chem 2008;16:1262-78

147 Young SE, Duvernay MT, Schulte ML, Lindsley CW, Hamm HE. Synthesis of indole derived protease-activated receptor 4 antagonists and characterization in human platelets. Plos One 2013;8:e65528

148 Holinstat M, Bray PF. Protease receptor antagonism to target blood platelet therapies. Clin Pharm Ther 2016;99:72-81

149 Dugina TN, Kiseleva EV, Chistov IV, Umarova BA, Strukova SM. Receptors of the PAR family as a link between blood coagulation and inflammation. Biochem 2002;67:65-74

150 Ramachandran R. Developing PAR1 antagonists: minding the endothelial gap. Disc Med 2012;13:425-31

151 Weiler H, Ruf W. ACTIVATED PROTEIN C IN SEPSIS: THE PROMISE OF NON-ANTICOAGULANT ACTIVATED PROTEIN C. Curr Opin Hematol 2008;15:487-93

152 Kerschen EJ, Fernandez JA, Cooley BC, et al. Endotoxemia and sepsis mortality reduction by non-anticoagulant-activated protein C. J Exp Med 2007;204:2439-48

153 Ferkau A, Gillmann HJ, Mischke R, et al. Infection-associated platelet dysfunction of canine platelets detected in a flow chamber model. BMC Vet Res 2013;9:112

154 Totani L, Dell'Elba G, Martelli N, et al. Prasugrel inhibits plateletleukocyte interaction and reduces inflammatory markers in a model of endotoxic shock in the mouse. Thromb Haemost 2012; 107:1130-40

155 Camerer E, Cornelissen I, Kataoka H, et al. Roles of proteaseactivated receptors in a mouse model of endotoxemia. Blood 2006;107:3912-21

156 Camerer E, Duong DN, Hamilton JR, Coughlin SR. Combined deficiency of protease-activated receptor- 4 and fibrinogen recapitulates the hemostatic defect but not the embryonic lethality of prothrombin deficiency. Blood 2004;103:152-4

157 Morrow DA, Braunwald E, Bonaca MP, et al. Vorapaxar in the secondary prevention of atherothrombotic events. N Engl J Med 2012;366:1404-13
158 Tricoci P, Huang Z, Held C, et al. Thrombin-receptor antagonist vorapaxar in acute coronary syndromes. N Engl J Med 2012; 366:20-33

159 Wong PC, Seiffert D, Bird JE, et al. Blockade of protease-activated receptor-4 (PAR4) provides robust antithrombotic activity with low bleeding. Science Transl Med 2017;9:371

160 Borensztajn K, Peppelenbosch MP, Spek CA. Factor Xa: at the crossroads between coagulation and signaling in physiology and disease. Trends Mol Med 2008;14:429-40

161 Bunnett NW. Protease-activated receptors: how proteases signal to cells to cause inflammation and pain. Semin Thromb Hemost 2006;((32, Suppl 1):39-48

162 Cirino G, Severino B. Thrombin receptors and their antagonists: an update on the patent literature. Exp Opin Ther Patents 2010; 20:875-84

163 Coughlin SR. Protease-activated receptors in hemostasis, thrombosis and vascular biology. J Thromb Haemost 2005;3:1800-14

164 Hamilton JR. Protease-activated receptors as targets for antiplatelet therapy. Blood Rev 2009;23:61-5

165 Hirano K, Kanaide H. Role of protease-activated receptors in the vascular system. J Atheroscler Thromb 2003;10:211-25

166 Krupiczojc MA, Scotton CJ, Chambers RC. Coagulation signalling following tissue injury: focus on the role of factor Xa. Int J Biochem Cell Biol 2008;40:1228-37

167 Macfarlane SR, Seatter MJ, Kanke T, Hunter GD, Plevin R. Proteinase-activated receptors. Pharmacol Rev 2001;53:245-82

168 Patterson C, Stouffer GA, Madamanchi N, Runge MS. New tricks for old dogs: nonthrombotic effects of thrombin in vessel wall biology. Circ Res 2001;88:987-97

169 Ruf W, Dorfleutner A, Riewald M. Specificity of coagulation factor signaling. J Thromb Haemost 2003;1:1495-503

170 Saban R, D'Andrea MR, Andrade-Gordon P, et al. Regulatory network of inflammation downstream of proteinase-activated receptors. BMC physiology 2007;7:3

171 Traynelis SF, Trejo J. Protease-activated receptor signaling: new roles and regulatory mechanisms. Curr Opin Hematol 2007; $14: 230-5$

172 Trejo J. Protease-activated receptors: new concepts in regulation of $G$ protein-coupled receptor signaling and trafficking. J Pharmacol Exp Ther 2003;307:437-42

173 Wang H, Ubl JJ, Reiser G. Four subtypes of protease-activated receptors, co-expressed in rat astrocytes, evoke different physiological signaling. Glia 2002;37:53-63 